\title{
THE
}

\section{Concordance of Self-Report and Measured Height and Weight of College Students}

Virginia Quick

Carol Byrd-Bredbenner

Suzanne Shoff

Adrienne A. White

Barbara Lohse

See next page for additional authors

Follow this and additional works at: https://digitalcommons.uri.edu/nfs_facpubs

This is a pre-publication author manuscript of the final, published article.

Creative Commons License

\section{c) (i) $\Theta$}

This work is licensed under a Creative Commons Attribution-Noncommercial-No Derivative Works 4.0 License.

\section{Citation/Publisher Attribution}

Quick, V., Byrd-Bredbenner, C., Shoff, S., White, A. A., Lohse, B., Horacek, T., Kattelmann, K.,...Greene, G. (2015). Concordance of Self-Report and Measured Height and Weight of College Students. Journal of Nutrition Education and Behavior, 27(1), 94-98. doi: 10.1016/j.jneb.2014.08.012

Available at: https://doi.org/10.1016/j.jneb.2014.08.012

This Article is brought to you for free and open access by the Nutrition and Food Sciences at DigitalCommons@URI. It has been accepted for inclusion in Nutrition and Food Sciences Faculty Publications by an authorized administrator of DigitalCommons@URI. For more information, please contact digitalcommonsgroup@uri.edu. 


\section{Authors}

Virginia Quick, Carol Byrd-Bredbenner, Suzanne Shoff, Adrienne A. White, Barbara Lohse, Tanya Horacek, Kendra Kattelmann, Beatrice Phillips, Sharon L. Hoerr, and Geoffrey Greene 


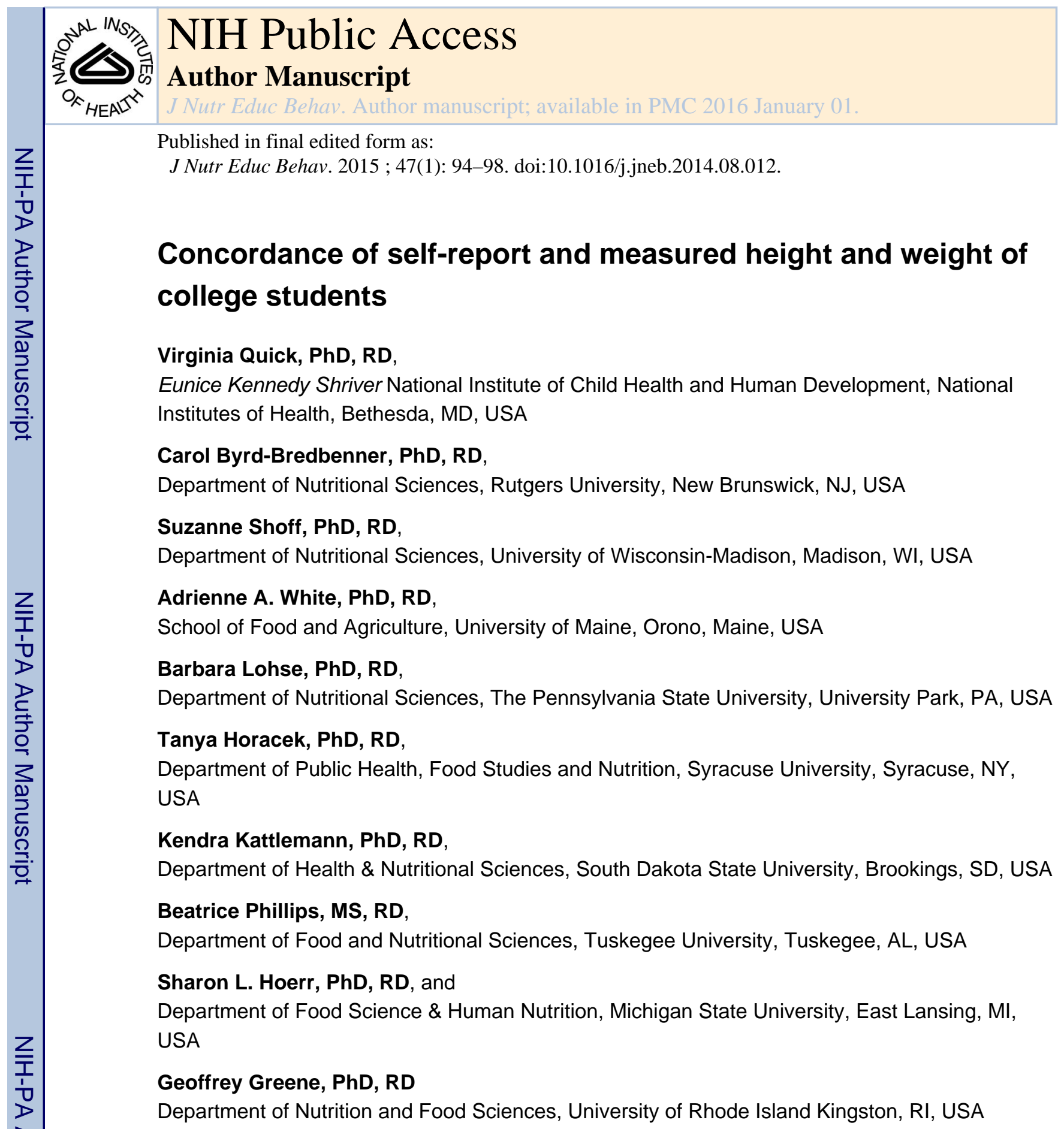

\begin{abstract}
(C) 2014 Society for Nutrition Education and Behavior. All rights reserved.

Corresponding author: Virginia Quick, PhD, RD, Eunice Kennedy Shriver National Institute of Child Health and Human Development, National Institutes of Health, Division of Intramural Population Health Research, 6100 Executive Blvd, Rm. 7B13B, Bethesda, MD, 20892, USA, gingermquick@ gmail.com, Phone: 1-301-435-6932, Fax: 1-301-402-2084.

Publisher's Disclaimer: This is a PDF file of an unedited manuscript that has been accepted for publication. As a service to our customers we are providing this early version of the manuscript. The manuscript will undergo copyediting, typesetting, and review of the resulting proof before it is published in its final citable form. Please note that during the production process errors may be discovered which could affect the content, and all legal disclaimers that apply to the journal pertain.

Funding Disclosure: None of the authors have any funding disclosures.
\end{abstract}


Objective-This study examined associations between college students' self-report and measured height and weight.

Methods-Participants ( $\mathrm{N}=1686)$ were $77 \%$ White, $62 \%$ female, $18-24 \mathrm{yr}$ of age (mean 19.1 $\pm 1.1 \mathrm{SD}$ ), and enrolled at 8 U.S. universities. BMI was calculated for self-report (via online survey) and measured (taken by trained researchers) height and weight, and categorized as normal ( 18.5 to $<25$ ), overweight ( 25 to $<30$ ), obese ( 30 to $<35$ ), and morbidly obese ( 235 ).

Results-Concordance of self-report vs. objectively measured BMI groups using Chi-square revealed $93 \%$ were accurate, $4 \%$ underestimated, and $2.7 \%$ overestimated. Pearson correlations and adjusted linear regression revealed significant associations between self-report and measured BMI $(r=0.97, P<.001)$ and BMI adjusted for age, gender and race/ethnicity $\left(\mathrm{R}^{2}=0.94\right)$. Concordance was also high between BMI categories $(\kappa=0.77, P<.001)$.

Conclusions and Implications-Findings provide support for the utility of self-report height and weight for survey research in college students.

\section{Keywords}

self-report; height; weight; body mass index; college students

\section{INTRODUCTION}

Many research studies include weight and height as primary outcomes. Although having trained personnel conduct direct measurements of body weight and height using research quality equipment and standardized techniques is considered the "gold standard" in research, ${ }^{1}$ financial and/or logistical considerations (e.g., geographic distance between researchers and participants) frequently preclude the application of this gold standard. This can be a problem for the many research studies that use weight and height or Body Mass Index (BMI) as primary outcomes. Self-reported body weight and height data are easy and cost-effective to obtain, ${ }^{2}$ but often viewed as a study limitation and considered insufficiently accurate for research studies. Previous investigations have found good concordance between measured and self-reported height and weight among youth (ages 15-25 years) and adults (ages 30-75). ${ }^{3-5}$ However, little is known about the accuracy of self-reported weight and height among young adults enrolled in college. Some studies suggest that college students who are female and/or overweight tend to overestimate height and underestimate weight making it difficult to have confidence in self-reported measurements in this population. ${ }^{6,7}$

Calculating BMI data in studies of young adults is important given people this age experience increases in weight gain, averaging $15 \mathrm{~kg}$ over 15 years placing them at risk for cardiovascular disease and other obesity-related diseases. ${ }^{8-10}$ For the majority of young adults who transition to college, weight gain may be related to changes in their food environment and physical activity levels. ${ }^{11,12}$ Studies of college students often use selfreported height and weight data to track the prevalence of overweight and obesity, ${ }^{13}$ which helps to inform obesity prevention and intervention efforts. Thus, information on the accuracy of students' self-reports of height and weight to estimate rates of overweight and obesity is important. 
BMI is a continuous variable calculated from height and weight that is often classifed into BMI categories (i.e., underweight $<18.5 \mathrm{~kg} / \mathrm{m}^{2}$, normal 18.5 to $<25 \mathrm{~kg} / \mathrm{m}^{2}$, overweight 25 to $<30 \mathrm{~kg} / \mathrm{m}^{2}$, obese 30 to $<35 \mathrm{~kg} / \mathrm{m}^{2}$ and morbidly obese $\left.35 \mathrm{~kg} / \mathrm{m}^{2}\right) .{ }^{14}$ No studies could be located that compared the concordance of BMI categories in a large, ethnically diverse population of young adults enrolled in college. Thus, the purpose of this study was to determine the accuracy of BMI categories when using self-report versus measured height and weight among college students from 8 universities. If self-reports of body weight and height are determined to be reasonably accurate, self-reported data in calculating BMI could be viewed with greater confidence.

\section{METHODS}

The university partners in the United States Department of Agriculture Multistate Healthy Campus Research Consortium that focuses on the health of young adults conducted this survey. This study was approved by the Institutional Review Boards of these participating universities: Michigan State University, South Dakota State University, Syracuse University, The Pennsylvania State University, Tuskegee University, University of Rhode Island, University of Maine, University of Wisconsin, and Rutgers University.

Participants aged 18 to 24 years enrolled at these first eight universities named above were recruited to participate in the Project WebHealth behavioral intervention using verbal announcements at student gatherings, flyers, and postings to university listservs. Eligibility criteria included having a BMI $>.18 .5 \mathrm{~kg} / \mathrm{m}^{2}$, not being pregnant or lactating, and not majoring in nutrition or exercise science. ${ }^{15}$ Only baseline data were used in the study reported here. Response rate to the overall Project WebHealth study are reported elsewhere. ${ }^{16}$ However, it is important to note that there were no statistical significant demographic (i.e.g, age, gender, race/ethnicity) differences between participants ( $n=1686)$ and non-participants with online survey data $(\mathrm{n}=557)$, except non-participants were significantly more likely to self-report slightly higher BMIs compared to participants $(t=2.28, \mathrm{p}=0.023)$.

\section{Data Collection}

Eligible participants gave informed consent and completed online questionnaires that included demographic measures (i.e., age, sex, college major, and race/ethnicity), and selfreported height and weight, which took about 30 minutes to complete. Participants also scheduled an appointment to complete physical assessments.

To prepare for the physical assessments, participants were instructed to refrain from eating or drinking caloric beverages for 4 hours and to avoid high intensity exercise for 24 hours prior to the assessment, and to wear light clothing. Trained research personnel used standardized procedures ${ }^{1}$ and measured the participants' weight $(\mathrm{kg})$ and height $(\mathrm{cm})$ in duplicate. Weight was measured to the nearest 0.25 pound with a calibrated digital or balance beam scale and height was measured to the neared 0.25 inch using a wall-mounted stadiometer. 
Researchers used the height and weight of each study participant to derive two BMI estimates (i.e., self-reported BMI and measured BMI). ${ }^{14}$ Both self-reported and measured BMI were used as both linear and categorical variables (i.e., underweight $<18.5 \mathrm{~kg} / \mathrm{m}^{2}$, normal 18.5 to $<25 \mathrm{~kg} / \mathrm{m}^{2}$, overweight 25 to $<30 \mathrm{~kg} / \mathrm{m}^{2}$, obese 30 to $<35 \mathrm{~kg} / \mathrm{m}^{2}$ and morbidly obese $\left.\geq 35 \mathrm{~kg} / \mathrm{m}^{2}\right) .{ }^{14}$ Self-reported and measured body weight and height also were categorized and coded into normal (i.e., BMI 18.5 to $<25=$ coded 0 ) and overweight/obese (i.e., BMI $\geq 25$ = coded 1 ) weight status groups. BMI misclassification groups (i.e., accurate-, under- and over-reporting) were created by taking the difference between values of self-report and measured weight status groups. Scores deviating from 0 indicated BMI group misclassification (i.e., -1 indicated underreporting and 1 indicated overreporting).

\section{Data analysis}

Descriptive statistics defined demographic variables and self-reported and measured BMI. Paired t-tests were used to determine statistical significant differences between measured and self-reported height and weight by gender. Chi-square tests were used to determine if significant differences in BMI misclassification groups occurred between genders.

Additionally, correlations between self-report and measured BMI using BMI classification groups (i.e., underweight $<18.5 \mathrm{~kg} / \mathrm{m}^{2}$, normal 18.5 to $<25 \mathrm{~kg} / \mathrm{m}^{2}$, overweight 25 to $<30$ $\mathrm{kg} / \mathrm{m}^{2}$, obese 30 to $<35 \mathrm{~kg} / \mathrm{m}^{2}$ and morbidly obese $35 \mathrm{~kg} / \mathrm{m}^{2}$ ) were conducted using Pearson's correlation, and agreement level (i.e., concordance) was calculated using kappa tests. Linear regression (unadjusted and adjusted for gender, age, and race/ethnicity) of measured BMI (dependent variable) with self-report BMI (independent variable) also were conducted. Analyses were performed using SPSS 21 (Chicago, IL).

\section{RESULTS}

Most participants ( $\mathrm{N}=1686)$ were female (62\%), white (77\%), and had a mean age of 19.1 \pm 1.1 SD years (Table 1). Most participants also were within a normal weight range with measured $\mathrm{BMI}=23.9 \pm 4.1 \mathrm{SD} \mathrm{kg} / \mathrm{m}^{2}$.

Paired $t$-tests indicate that men were significantly more likely to overreport their weight and height (Weight: $t=5.29, \mathrm{df}=633, P<.001$; Height: $t=18.51 \mathrm{df}=633, P<.001$ ), while women were significantly more likely to underreport their weight $(t=-4.06, \mathrm{df}=1051, p<$. $001)$ and overreport their height $(t=7.97, \mathrm{df}=1051, P<.001)$. Concordance of self-report vs. measured BMI classification groups using chi-square revealed $93 \%$ were accurate, $4 \%$ self-reported normal when actually overweight, and $2.7 \%$ self-reported overweight when actually normal. Similar findings were found when stratified by gender, except that females were significantly $(P=.009)$ more accurate than males (95\% vs. $91 \%)$ (Table 1$)$.

Pearson correlations were high between measured and self-reported heights, weights and BMIs $(r=0.98,0.99,0.97, P<0.001$, data not shown). Additionally, in linear regression models of measured and self-reported BMI, no differences in the unadjusted and adjusted $\mathrm{R}^{2}$ (for age, gender, race/ethnicity) $\left(\mathrm{R}^{2}=0.94\right)$ were identified. Gender, age, and race/ethnicity were not predictors in the adjusted models between measured and self-reported BMI. 
As determined by Landis and Koch's kappa test magnitude guidelines, ${ }^{17}$ substantial concordance $(\kappa=0.77, P<0.001)$ between measured and self-reported BMI was noted (Table 2). There were slight differences in concordance among subgroups: men $\kappa=0.75$, women $\kappa=0.79$, white $\kappa=0.80$, black $\kappa=0.71$, Hispanic $\kappa=0.90$, Asian/Pacific Islander $\kappa=0.62$, and Other race/ethnicity $\kappa=0.78$. There was not a vast difference in concordance among college majors (agriculture/physical sciences/business $\kappa=0.81$, liberal arts/education/ humanities/social sciences $\kappa=0.79$, and other/undeclared $\kappa=0.75$ ). The sensitivity of selfreported BMI among normal weight participants was $96 \%$, but this decreased as BMI increased. However, specificity, which measures the percentage of participants who are not identified as being in the correct measured BMI group, was over $87 \%$ for all BMI groups. The positive predictive value (i.e., PPV $=$ \# of true positives/\# of true positives $+\#$ of false positives) was also lower compared to the negative predictive value (i.e., NPV $=\#$ of true negatives/\# of true negatives + number of false negatives) among all BMI groups.

\section{DISCUSSION}

In general, young adults enrolled in college give accurate self-reports of their height and weight used to derive BMI scores for weight categorization. There were some differences in BMI misclassification between women and men as well as between normal and overweight students, and concordance between self-reported and measured BMI categories in race/ ethnic subgroups, but overall concordance was moderate to substantial.

As supported by previous studies, ${ }^{6,18}$ results from our paired t-tests indicated that college women were more likely to underreport body weight and overreport height; however gender differences did not emerge in our regression analyses. It is important to note that among women the average underreporting of weight was 0.6 pounds and average overreporting of height was 0.2 inches; this difference in weight could be attributed to variation in time of day or their menstrual cycles when their weight was measured. Similarly, among men the average overreporting of weight and height were small, equaling 1.2 pounds and 0.6 inches, respectively. Thus, men had lower self-report BMIs than measured BMI, which is partially due to the BMI formula being more sensitive to inaccuracies of height than weight. Women might have a tendency to underreport their body weight more than men, perhaps because many have poorer body satisfaction and greater desire to appear thinner. ${ }^{19}$ However, a recent study by Gunnare and colleagues found that body satisfaction was not associated with weight accuracy. ${ }^{6}$ Instead, they found that having a high BMI was one of the most important predictors of underreporting. ${ }^{6}$ Indeed, in our study we found that for both college women and men, the sensitivity of self-reported BMI decreased as BMI increased suggesting that heavier college students wish to conform to social norms and make attempts to appear thinner and/or leaner by underreporting weight.

It is unclear as to why there were some differences in concordance between self-reported and measured BMI by race/ethnic groups. The variations seen in race/ethnic groups may be due to differences in body size preferences by ethnic groups that could lead to under- or over-reporting of body weight and height. Alternatively, there might not have been enough people in each category to make stable comparisons. More studies of racially/ethnically diverse young adults are needed to better understand the influence of race/ethnicity on 
accuracy of self-reported weight and height. Overall though, concordance between selfreport and measured BMI by race/ethnic groups was evidenced. However, the regression models of self-report and measured BMI suggests that race/ethnicity, age and gender do not influence accuracy of self-reported weight and height data. Thus, more research is needed to examine how sample characteristics such as race/ethnicity may influence accuracy of selfreporting weight and height data.

Many researchers have examined factors that may influence under- and over-reporting of BMI such as dietary restraint, physical activity level, and self-weighing frequency, $5,6,19$ and they continue to find this of importance in planning and interpreting epidemiologic studies based on self-reported height and weight. However, in the current study, substantial overall congruence was found between self-reported and measured heights, weights, and calculated BMI among all participants, and by each subgroup of women, men, and race/ethnic group. Although, the sensitivity of self-reported BMI decreased among heavier BMI weight status groups, the specificity, positive, and negative predictive values remained high.

Several issues limit interpretation of the findings. This sample included self-selected participants that were mostly white (77\%), thus generalizations to other college populations with differing sociodemographics and weight statuses should be made with caution.

Additionally, social desirability bias in self-reporting of weight and height is possible as participants knew that their weight and height would be measured during the study. Finally, this was a cross-sectional study and findings are not applicable to longitudinal studies. However, Zagorsky and Smith ${ }^{20}$ used self-reported height and weight data for their longitudinal study of young adults and found that college students and same-age non-college students are similar in their reports of height and weight and consistently underestimate their body weight.

\section{Acknowledgements}

Research was supported in part by the intramural research program of the National Institutes of Health (NIH), Eunice Kennedy Shriver National Institute of Child Health and Human Development; USDA National Research Initiative 2005-35215-154121541; NIH Grant M01RR10732; New Jersey, Maine, Rhode Island, Michigan, South Dakota, and Wisconsin Agricultural Experiment Stations; Syracuse University.

\section{References}

1. Lohman, T.; Roche, A.; Martorell, R. Anthropometric standardization reference manual. Champaign, IL: Human Kinetics Publishers, Inc; 1988.

2. Stunkard A, Albaum J. The accuracy of self-reported weights. American Journal of Clinical Nutrition. 1981; 34:1593-1599. [PubMed: 7270483]

3. Kreatsoulas C, Hassan A, Subramanian S, Fleegler E. Accuracy of self-reported height and weight to determine body mass index among youth. Child \& Adolescent Behavior. 2014; 2:126.

4. Sherry B, Jefferd M, Grummer-Strawm L. Accuracy of adolescent self-report of height and weight in assessing overweight status: a literature review. Archives of Pediactric Adolescent Medicine. 2007; 161:1154-1161.

5. Nyholm M, Gullberg B, Merlo J, Lundqvist-Persson C, Rastam L, Lindblad U. The validity of obesity based on self-reported weight and height: Implications for population studies. Obesity (Silver Spring). 2007; 15:197-208. [PubMed: 17228048] 
6. Gunnare N, Silliman K, Morris M. Accuracy of self-reported weight and role of gender, body mass index, weight satisfaction, weighing behavior, and physical activity among rural college students. Body Image. 2013; 10(3):406-410. [PubMed: 23419637]

7. Larsen J, Ouwens M, Engels R, Eisinga R, van Strien T. Validity of self-reported weight and height and predictors of weight bias in female college students. Appetite. 2007; 50(2-3):386-390. [PubMed: 18006115]

8. Truesdale K, Stevens J, Lewis C, Schreiner P, Loria C, Cai J. Changes in risk factors for cardiovascular disease by baseline weight in young adults who maintain or gain weight over 15 years: the CARDIA study. International Journal of Obesity. 2006; 30(9):1397-1407. [PubMed: 16534519]

9. Williamson D, Kahn H, Remington P, Anda R. The 10-year indicidence of overweight and major weight gain in U.S. adults. Archives of Internal Medicine. 1990; 150(3):665-672. [PubMed: 2310286]

10. Bray G. Medical consequences of obesity. J Clin Endocrinol Metab. 2004; 89(6):2583-2589. [PubMed: 15181027]

11. Bray S, Born H. Transition to university and vigorous physical activity: implications for health and well-being. J Am Coll Health. 2004; 52:181-188. [PubMed: 15018429]

12. Horacek T, Erdman M, Reznar M, et al. Evaluation of food store environment on and near the campus of 15 post-secondary institutions. American Journal of Health Promotion. 2013; 27(4):e81-e90. [PubMed: 23448419]

13. American College of Health Association. American College of Health Association - National college health assessment spring 2008 reference group data report (abridged). J Am Coll Health. 2009; 57:477-488. [PubMed: 19254888]

14. U.S. Department of Health and Human Services. Clinical guidelines on the identification, evaluation, and treatment of overweight and obesity in adults: The evidence report: NIH Publication, No. 98-4083. 1998.

15. Greene G, White AA, Hoerr S, et al. Impact of an online healthful eating and physical actiity program for college students. American Journal of Health Promotion. 2012; 27(2):47-58.

16. Greene G, Schembre $\mathrm{S}$, White AA, et al. Identifying clusters of college studnets at elevated health risk based on eating and exercise behaviors and psychosocial determinants of body weight. J Am Diet Assoc. 2011; 111:394-400. [PubMed: 21338738]

17. Landis J, Koch G. The measurement of observer agreement for categorical data. Biometrics. 1977; 33(1):159-174. [PubMed: 843571]

18. Mozumdar A, Liguori G. Correction equations to adjust self-reported height and weight for obesity estimates among college students. Res Q Exerc Sport. 2011; 82:391-399. [PubMed: 21957697]

19. McCabe R, McFarlane T, Polivy J, Olmsted M. Eating disorders, dieting and the accuracy of selfreported weight. Internationl Journal of Eating Disorders. 2001; 29:59-64.

20. Zagorsky J, Smith P. The Freshman 15: A critical time for obesity intervention or media myth. Social Sciences Quarterly. 2011; 92(5):1389-1407. 


\section{IMPLICATIONS FOR RESEARCH AND PRACTICE}

Despite these limitations, researchers can feel confident in the accuracy of college student's self-reported weight and height for cross-sectional studies. In conclusion, findings indicate self-reported body weight and height of young adults can be fairly accurate, and their use is supported when direct measurements are not feasible. 
Table 1

Sample Characteristics and Body Mass Index (BMI) Misclassification by Gender

\begin{tabular}{|c|c|c|c|}
\hline Characteristic & $\begin{array}{l}\text { All participants } \\
(\mathbf{N}=1686)\end{array}$ & $\begin{array}{c}\text { Female } \\
(n=1052)\end{array}$ & $\underset{(n=634)}{\text { Male }}$ \\
\hline & $\begin{array}{c}\text { Mean } \pm \text { SD or } \\
\mathbf{N}(\%)\end{array}$ & $\begin{array}{c}\text { Mean } \pm \text { SD or } \\
\mathbf{N}(\%)\end{array}$ & $\begin{array}{c}\text { Mean } \pm \text { SD or } \\
\mathbf{N}(\%)\end{array}$ \\
\hline Age, yr & $19.1 \pm 1.1$ & $19.0 \pm 1.0$ & $19.3 \pm 1.3$ \\
\hline \multicolumn{4}{|l|}{ Gender } \\
\hline Female & $1052(62.4)$ & $1052(100)$ & --- \\
\hline Male & $634(37.6)$ & --- & $634(100)$ \\
\hline \multicolumn{4}{|l|}{ Race/ethnicity 1} \\
\hline White, non-Hispanic & $1291(76.6)$ & $806(76.6)$ & $485(76.5)$ \\
\hline Black, non-Hispanic & $171(10.1)$ & $110(10.5)$ & $61(9.6)$ \\
\hline Hispanic/Latino & $54(3.2)$ & $37(3.5)$ & $17(2.7)$ \\
\hline Asian/Pacific Islander & $84(5.0)$ & $43(4.1)$ & $41(6.5)$ \\
\hline Other & $38(2.3)$ & $23(2.2)$ & $15(2.4)$ \\
\hline Unknown & $48(2.8)$ & $33(3.1)$ & $15(2.4)$ \\
\hline \multicolumn{4}{|l|}{ College Major } \\
\hline Agriculture, physical sciences, $\&$ business & $489(29.0)$ & $270(25.7)$ & $219(34.5)$ \\
\hline Liberal arts, education, humanities, \& social sciences & $321(19.0)$ & $242(23.0)$ & $79(12.5)$ \\
\hline Other or undeclared & $875(51.9$ & $539(51.2)$ & $336(53.0)$ \\
\hline \multicolumn{4}{|l|}{ Self-reported 1,2} \\
\hline Height, in. & $67.1 \pm 3.9$ & $65.0 \pm 2.7$ & $70.6 \pm 2.8$ \\
\hline Weight, lb. & $152.4 \pm 31.9$ & $140.4 \pm 26.4$ & $172.4 \pm 30.3$ \\
\hline BMI $\left(\mathrm{kg} / \mathrm{m}^{2}\right)$ & $23.7 \pm 3.8$ & $23.3 \pm 3.9$ & $24.2 \pm 2.6$ \\
\hline \multicolumn{4}{|l|}{ Measured } \\
\hline Height, in. & $66.8 \pm 3.7$ & $64.8 \pm 2.6$ & $70.0 \pm 2.7$ \\
\hline Weight, lb. & $152.3 \pm 32.3$ & $141.0 \pm 27.3$ & $171.2 \pm 31.1$ \\
\hline BMI $\left(\mathrm{kg} / \mathrm{m}^{2}\right)$ & $23.9 \pm 4.1$ & $23.6 \pm 4.1$ & $24.5 \pm 3.9$ \\
\hline \multicolumn{4}{|l|}{ BMI classification ${ }^{3}$} \\
\hline Accurate reporting & $1573(93.3)$ & $996(94.7)$ & $577(91.0)$ \\
\hline Underreporting & $68(4.0)$ & $36(3.4)$ & $32(5.0)$ \\
\hline Overreporting & $45(2.7)$ & $20(1.9)$ & $25(3.9)$ \\
\hline
\end{tabular}

J Nutr Educ Behav. Author manuscript; available in PMC 2016 January 01. 
